Article

\title{
Processing and Characterization of Bioplastics from the Invasive Seaweed Rugulopteryx okamurae
}

\author{
Ismael Santana (D), Manuel Félix (D), Antonio Guerrero (D) and Carlos Bengoechea * (D) \\ Higher Polytechnic School, University of Seville, Calle Virgen de África, 7, 41011 Sevilla, Spain \\ isantana@us.es (I.S.); mfelix@us.es (M.F.); aguerrero@us.es (A.G.) \\ * Correspondence: cbengoechea@us.es; Tel.: +34-954-557-179
}

Citation: Santana, I.; Félix, M.; Guerrero, A.; Bengoechea, C. Processing and Characterization of Bioplastics from the Invasive Seaweed Rugulopteryx okamurae. Polymers 2022, 14, 355. https:// doi.org/10.3390/polym14020355

Academic Editor: Jean-Marie Raquez

Received: 23 December 2021

Accepted: 10 January 2022

Published: 17 January 2022

Publisher's Note: MDPI stays neutral with regard to jurisdictional claims in published maps and institutional affiliations.

Copyright: (C) 2022 by the authors. Licensee MDPI, Basel, Switzerland. This article is an open access article distributed under the terms and conditions of the Creative Commons Attribution (CC BY) license (https:// creativecommons.org/licenses/by/ $4.0 /)$.

\begin{abstract}
The seaweed Rugulopteryx okamurae, from the Pacific Ocean, is considered an invasive species in the Mediterranean Sea. In this work, the use of this seaweed is proposed for the development of bio-based plastic materials (bioplastics) as a possible solution to the pollution produced by the plastic industry. The raw seaweed Rugulopteryx okamurae was firstly blended with glycerol (ratios: $50 / 50,60 / 40$ and 70/30), and subsequently, they were processed by injection molding at a mold temperature of 90,120 and $150{ }^{\circ} \mathrm{C}$. The rheological properties (frequency sweep tests and temperature ramp tests) were obtained for blends before and after processing by injection molding. The functional properties of the bioplastics were determined by the water uptake capacity (WUC) values and further scanning electron microscopy (SEM). The results obtained indicated that $\mathrm{E}^{\prime}$ was always greater than $E^{\prime \prime}$, which implies a predominantly elastic behavior. The 70/30 ratio presents higher values for both the viscoelastic moduli and tensile properties than the rest of the systems (186.53 $\pm 22.80 \mathrm{MPa}$ and $2.61 \pm 0.51 \mathrm{MPa}$, respectively). The WUC decreased with the increase in seaweed in the mixture, ranging from $262 \%$ for the $50 / 50$ ratio to $181 \%$ for the $70 / 30$ ratio. When carrying out the study on molded bioplastic 70/30 at different temperatures, the seaweed content did not exert a remarkable influence on the final properties of the bioplastics obtained. Thus, this invasive species could be used as raw material for the manufacture of environmentally friendly materials processed by injection molding, with several applications such as food packaging, control-release, etc.
\end{abstract}

Keywords: Rugulopteryx okamurae; bioplastics; DMA; injection molding; seaweed

\section{Introduction}

Rugulopteryx okamurae (RO), also known as Dictyota marginata, Dilophus marginatus, or Dictyota okamurae [1,2], is a species of brown algae belonging to the Dictyotaceae family, originally from the coasts of the warm and temperate northwestern Pacific Ocean (Korea, Japan, China, Taiwan and the Philippines) [3]. This alga has been introduced from the Pacific Ocean to the Mediterranean through the Strait of Gibraltar. The Spanish Mediterranean coasts and those of the Strait of Gibraltar present a highly favorable environment for the species, favoring its expansion and an increase in the derived impacts. Consequently, on 1 December 2020 it was included in the Spanish Catalog of Invasive Exotic Species since it represents one of the main threats to biodiversity in the Mediterranean, due to its ability to spread and adapt [4].

In 2020, García-Gómez et al. [5] reported that more than 3,000,000 $\mathrm{m}^{2}$ of the seabed of the Strait Natural Park was occupied by this invasive seaweed at different depths. The highest proportion of coverage occurs between 5 and $30 \mathrm{~m}$, reaching 85-96\%, while the smallest was found at greater depths or practically on the shores, 30-40 or 0-5 m (around $42-45 \%$ ). This invasive species not only has effects on the seagrass, but it should also be noted that 5000 tons of this Asian seaweed were dislodged from the beaches of Ceuta in 2015, and 400 tons from the beaches of Tarifa only in July 2020 [6]. 
The great technological development from the twentieth century to the present has caused an increase in environmental pollution. Among these advances, the industrial production of non-biodegradable plastic materials stands out [7]. At the beginning of the 21st century, the average consumption of plastic was $15 \mathrm{~kg} /$ year per person [8]. This also accounts for a large part of the pollution that is produced, both by the emission of greenhouse gases during their manufacture and disposal, as well as by their accumulation in landfills and a high presence in the oceans due to their low biodegradability [9]. Since the 1950s, more than 7800 million metric tons have been produced, of which more than $10 \%$ ends up in the oceans once disposed. This produces worrying impacts on the seabed, its biodiversity and people due to the consumption of fish contaminated with microplastics [10]. Thus, an annual consumption of 39,000 to 52,000 microplastic particles is estimated that can negatively affect health [11].

Nowadays, an important part of this development is inconceivable without taking care of the environment, and that is why there are increasingly more restrictive regulations and a greater and growing interest in finding biodegradable materials with properties similar to those of conventional plastics. The solution of conventional plastics is the use of bioplastics, which can be defined as those plastics made from a renewable source or those which are biodegradable [12,13]. This demand for bio-based raw materials will demand a huge amount of resources, which could be supplied by both agri-food wastes or invasive species with no applications in the local market. Underutilized invasive species would provide adequate biomass for processing, which would reduce their environmental impact. The present work proposes the use of the invasive seaweed RO from the bay of Algeciras (located in the Strait of Gibraltar) as a raw material to produce bioplastics. The use of the invasive seaweed $\mathrm{RO}$ to generate biodegradable materials would serve both to reduce the impact of algae in the Mediterranean biodiversity and find an alternative to fossil-based plastics that pollute the planet. Depending on their properties, algae are used for various applications, such as in cosmetic or bioplastic packaging industries [14].

One of the problems when replacing conventional plastics with bioplastics are the poorer mechanical properties of the latter during their processing and end use, which can limit their potential. As a solution, a plasticizer is added to improve its mechanical properties. According to IUPAC (International Union of Pure and Applied Chemistry), a plasticizer is defined as "a substance or material incorporated into another material to improve its flexibility, compliance or viability" [15]. Plasticizers generally have a high boiling point and carbon chains of between 14 and 40 carbons, with a molecular weight of between 300 and 600 [16]. Thanks to these characteristics, plasticizers can be inserted into the structure of the polymers that make up plastics, reorganizing their three-dimensional structure, reducing the intramolecular forces of the polymer and allowing its mobility [17]. Due to this function, the choice of plasticizer for the plastic to be developed is important, as it will affect its final properties. Other parameters to consider when choosing a plasticizer are the boiling or melting temperature, polarity or solvation. Moreover, little or no toxicity, such as that of fatty acid esters or vegetable glycerol, is desired when selecting a plasticizer [18].

The selection of the technique and conditions used when processing bioplastics is also highly influential in their final properties. It should be noticed that Mass Flow Rate (MFR) is also of extreme importance when selecting a processing technique for bioplastics. Some authors have pointed out that some biodegradable plastics, such as polylactide (PLA), experience a greater increase in MFR when increasing the processing speed than conventional plastics, such as low-density polyethylene (LDPE) [19]. This clearly affects the energy efficiency of the processing techniques. There are different techniques for processing bioplastics, such as compression molding, extrusion or injection molding, among others. Compression molding consists of two metal molds that apply a certain force on the sample to produce the bioplastic. As the sample flows into the mold, it acquires its shape [20]. Extrusion is the most widely used technique for processing polymers, and consists of a continuous process, where the polymer is transported through a barrel where it is heated to 
enhance its flowability through a final, conveniently shaped orifice. The polymer cools as it exits and results in a constant section solid [21]. Injection molding consists of the softening of a plastic material under the appropriate conditions and its subsequent introduction under pressure into the cavities of a mold, in which it is brought to a temperature at which the pieces can be extracted without deforming. The injection molding process can be divided into two main stages: injection and compaction. First, the substance to be molded is introduced into a tank that is heated to a certain temperature that allows the material to flow for subsequent injection into the mold, by means of a piston which exerts a certain pressure. This is typically called the injection stage. The compaction stage is the second part of the process and occurs with the sample already inside the cavities of the mold, which is heated to the molding temperature. In the case of biopolymers, the molding temperature can be higher than that of the cylinder, so as to promote crosslinking and fix the structure. During this stage, the injected homogeneous mixture is subjected to a certain stable pressure by the piston until its extraction [20]. Among all the different techniques available for dry bioplastic processing, this work selected injection molding due to its versatility and scalability.

This processing technique has been already used to manufacture bioplastics from gluten [22], soy protein [23] or blood plasma from the meat industry [24], among others. Even if different examples of the development of bioplastics have already been reported [14]. There is no such information from the invasive macroalgae RO. The qualities that macroalgae offer (low cost, low toxicity, proper mechanical properties) make them a good candidate for producing bioplastics [25].

The aim of this work has been the development and characterization of bioplastic materials based on $\mathrm{RO}$ seaweed. To this end, $\mathrm{RO}$ was firstly blended with glycerol (ratios: $50 / 50,60 / 40$ and 70/30), and subsequently, bioplastics were processed at $120{ }^{\circ} \mathrm{C}$. Subsequently, the effect of mold temperature was also analyzed by sample processing at 90 and $150{ }^{\circ} \mathrm{C}$ (RO/GLY ratio: 70/30). The rheological properties (frequency sweep tests and temperature ramp tests) were obtained for blends before and after processing by injection molding, whereas the functional properties of the bioplastics obtained were assessed by water uptake capacity (WUC) and electron scan microscopy (SEM).

\section{Materials and Methods}

\subsection{Materials and Sample Preparation}

The seaweed RO used in the present study was gently supplied by the Andalusian Institute for Agricultural, Fisheries, Food and Organic Production Research and Training (IFAPA, Puerto Real, Spain). The RO was hand-picked from the bay of Algeciras, and subsequently freeze dried. Freeze-dried algae samples were ground in a kitchen blender (Mambo10070, CECOTEC, Valencia, Spain) at maximum speed, obtaining a flour where the diameters of most particles ( 90\%) were within the 10 to $100 \mu \mathrm{m}$ range. GLY was used as plasticizer (Panreac Química S.A (Castellar del Vallès, Spain). The proximate composition of the seaweed is $18.47 \pm 0.35 \%$ ashes, $13.48 \pm 0.26 \%$ water, $9.76 \pm 0.16 \%$ proteins (conversion factor $N$-protein: 4.92 [26]) and $11.63 \pm 0.22 \%$ lipids.

Bioplastics were obtained in a two-step method: (i) RO and glycerol (GLY) was mixed in a two-blade counter-rotating batch mixer Haake Polylab QC (ThermoHaake, Karlsruhe, Germany) at room temperature and $50 \mathrm{rpm}$ until system homogeneity $(60,10$ and $5 \mathrm{~min}$ for $\mathrm{RO} / \mathrm{GLY}$ ratios 50/50, 60/40 and 70/30, respectively); (ii) RO/GLY blends were injected in the lab-scale Minijet Piston Injection Molding System (ThermoHaake, Karlsruhe, Germany), obtaining $1 \times 10 \times 60 \mathrm{~mm}^{3}$ probes. The samples were processed at $60{ }^{\circ} \mathrm{C}$ (cylinder temperature), whereas the mold temperature was set at 90,120 or $150{ }^{\circ} \mathrm{C}$. The injection pressure was 500 bar ( $20 \mathrm{~s})$, whereas the post-injection pressure was $200 \mathrm{bar}(150 \mathrm{~s})$. These processing conditions were similar to those from plasma porcine protein [24].

Figure 1 shows the schematic process for the processing and characterization of bioplastics. 


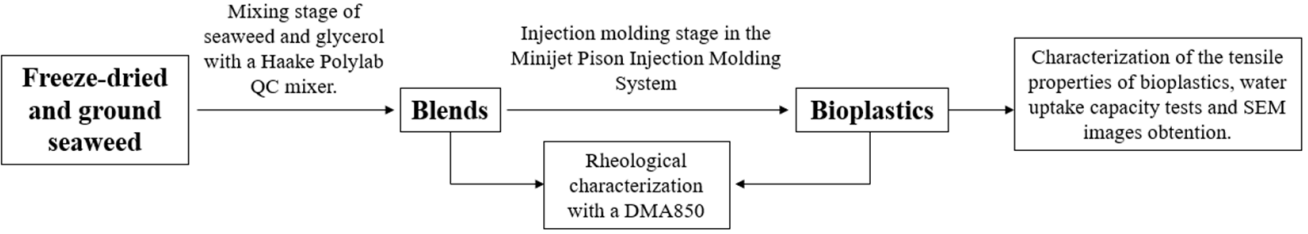

Figure 1. Scheme of the production process and characterization of bioplastics.

\subsection{Methods}

2.2.1. Rheological Characterization of RO/GLY Blends

Rheological Measurements

The RO/GLY blends obtained after the mixing stage were analyzed by dynamic mechanical analysis (DMA) in compression mode. Frequency sweep tests (from 0.1 to $10 \mathrm{~Hz}$ ) and temperature ramp tests (from -50 to $150^{\circ} \mathrm{C}$ ) were performed using a DMA850 (TA Instruments, Wakefield, MA, USA). All DMA tests were performed within the linear viscoelastic region, which was determined prior to any measurement by strain sweep tests at $1 \mathrm{~Hz}$. Frequency sweep tests were performed at constant temperature $\left(25^{\circ} \mathrm{C}\right)$, whereas temperature ramp tests were performed at a constant frequency $(1 \mathrm{~Hz})$. DMA tests were performed using the $15 \mathrm{~mm}$ diameter parallel plates geometry.

\subsubsection{Characterization of the RO-Based Bioplastics}

Rheological Measurements

Final bioplastics were characterized by DMA tests with a tension clamp as geometry. For these tests, rectangular probes $(10 \mathrm{~mm} \times 1 \mathrm{~mm} \times 15 \mathrm{~mm})$ were analyzed in the DMA 850 (TA Instruments, MA, USA). Frequency sweep tests (from 0.1 to $10 \mathrm{~Hz}$ ) and temperature ramp tests (from -30 to $180^{\circ} \mathrm{C}$ ) were performed using a DMA850 (TA Instruments, MA, USA). All DMA tests were performed within the linear viscoelastic region, which was determined prior to any measurement by strain sweep tests at $1 \mathrm{~Hz}$. Frequency sweep tests were performed at constant temperature $\left(25^{\circ} \mathrm{C}\right)$, whereas temperature ramp tests were performed at a constant frequency $(1 \mathrm{~Hz})$.

\section{Tensile Properties}

Stress-strain curves were obtained in uniaxial tensile tests until fracture using a RSA3 (TA Instruments, MA, USA). From these tests, three parameters were obtained: Young's modulus $(\mathrm{E})$, maximum stress $\left(\sigma_{\max }\right)$ and maximum strain $\left(\varepsilon_{\max }\right)$. These tests were performed using rectangular probes $(60 \mathrm{~mm} \times 10 \mathrm{~mm} \times 1 \mathrm{~mm})$ according to the standard ISO 527-2 [27]. All tensile tests were carried out at a constant elongation rate of $1 \mathrm{~mm} \cdot \mathrm{min}^{-1}$ and room temperature.

\section{Water Uptake Capacity (WUC)}

Water uptake capacity (WUC) was determined as follows [28]: bioplastic samples were first dried at $50{ }^{\circ} \mathrm{C}$ for $24 \mathrm{~h}$ and weight $\left(\mathrm{w}_{1}\right)$; then, dried samples were immersed for $24 \mathrm{~h}$ in $100 \mathrm{~mL}$ of deionized water and weighed $\left(\mathrm{w}_{2}\right)$. Finally, samples were lyophilized for $24 \mathrm{~h}$ and weighed $\left(\mathrm{w}_{3}\right)$. WUC and soluble matter loss (SML) were calculated using Equations (1) and (2):

$$
\begin{aligned}
& \operatorname{WUC}(\%)=\frac{\left(\mathrm{w}_{2}-\mathrm{w}_{3}\right)}{\mathrm{w}_{3}} \cdot 100 \\
& \operatorname{SML}(\%)=\frac{\left(\mathrm{w}_{1}-\mathrm{w}_{3}\right)}{\mathrm{w}_{1}} \cdot 100
\end{aligned}
$$

Scanning Electron Microscopy (SEM)

Freeze-dried matrices obtained after WUC were cut into small pieces $(\sim 2.5 \mathrm{~mm})$, gold coated and, finally, examined by SEM, in a ZEISS EVO (Oberkochen, Germany). A beam current of $18 \mathrm{pA}$ and a working distance of 7.5-8.5 mm were employed in the 
microscope, with an acceleration voltage of $10 \mathrm{kV}$. Image analyses were obtained at $1000 \times$, $500 \times$ and $200 \times$ magnification. Moreover, they were analyzed by the imaging software ImageJ (Bethesda, MD, USA) [29].

\subsection{Statistical Analysis}

All measurements were carried out at least in triplicate. The statistical analysis was carried out using the STATGRAPHICS Centurion XVIII software (The Plains, VA, USA). The standard deviation for some selected parameters was included. Significant differences $(p<0.05)$ were indicated by superscript letters.

\section{Results and Discussion}

\subsection{Influence of the Rugulopteryx okamurae/Glycerol (RO/GLY) Ratio}

3.1.1. Blends

Mixing

After freeze drying and milling, RO seaweed was thoroughly mixed with glycerol (GLY) to obtain a homogeneous blend that was eventually injected. A picture of the resulting blends can be found in the Supplementary Material (Figure S1. Visual appearance of RO/GLY blends at different ratios (from left to right: 50/50,60/40, 70/30)). Figure 2 shows the evolution of torque $(\mathrm{A})$ and temperature $(\mathrm{B})$ with mixing time for blends obtained at different RO/GLY ratios (50/50,60/40 and 70/30). An apparent increase in both torque and temperature values was observed during the whole mixing stage as the ratio of seaweed in the blends increased, and was especially noticeable for the 70/30 system. The greater the RO/GLY ratio (i.e., the lower amount of plasticizer in the blend) resulted in a lowering of the free volume among the polymeric chains present in the seaweed biomass. As a consequence, there was greater friction which led to thermal energy dissipation that was detected as a temperature rise [22]. Moreover, 50/50 and 60/40 systems achieve a steady value for both torque $\left(2.2,2.8 \mathrm{~N} \cdot \mathrm{m}\right.$, respectively) and temperature $\left(28.7\right.$ and $33.4{ }^{\circ} \mathrm{C}$, respectively) after around $10 \mathrm{~min}$ of mixing time. At that time, both torque and temperature of the system with the greatest $\mathrm{RO}$ content $(70 / 30)$ displayed much greater values $(13.2 \mathrm{~N} \cdot \mathrm{m}$, $43.4^{\circ} \mathrm{C}$, respectively) than the rest. Moreover, this system evolves into a sudden growth of both parameters from around $8 \mathrm{~min}$, which may be related to a certain strengthening of the sample promoted by the greater proximity of the different compounds present in the biomass.

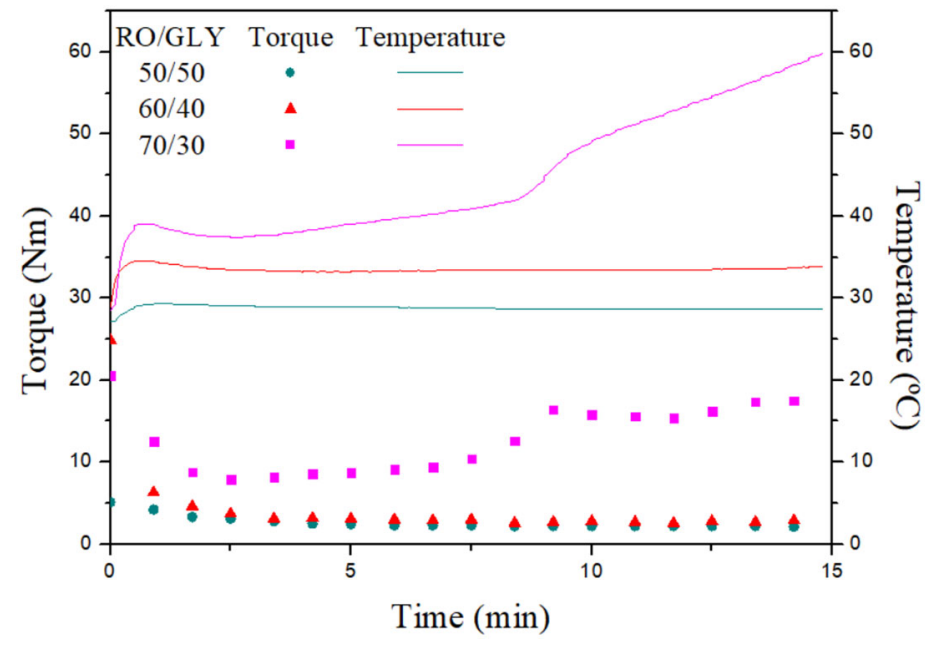

Figure 2. Torque and temperature values for different RO/Gly systems during the mixing stage. 
Specific mechanical energy (SME) of every system at a specific time from the mixing curves:

$$
\mathrm{SME}=\frac{\omega}{\mathrm{m}} \int_{0}^{\mathrm{t}_{\text {mix }}} \mathrm{M}(\mathrm{t}) \delta(\mathrm{t})
$$

where $\omega$ (in rad/s) is the mixing speed, $\mathrm{m}$ (in $\mathrm{g}$ ) the sample mass, $\mathrm{M}(\mathrm{t})$ (in $\mathrm{N} \cdot \mathrm{m}$ ) the torque and $t_{\text {mix }}$ (in s) the mixing time. In order to avoid the effect of the second strengthening in $70 / 30$, a $t_{\text {mix }}$ of 5 min was selected for the estimation of SME shown in Table 1.

Table 1. Specific Mechanical Energy (SME) involved in the mixing of different RO/GLY systems ( $\mathrm{t}_{\text {mix }}$ : $5 \mathrm{~min})$.

\begin{tabular}{cc}
\hline RO/GLY & SME (kJ/kg) \\
\hline $50 / 50$ & $208 \pm 37$ \\
\hline $60 / 40$ & $328 \pm 50$ \\
\hline $70 / 30$ & $805 \pm 182$ \\
\hline
\end{tabular}

It is quite apparent that $\mathrm{SME}$ is greater as the seaweed content increases within the formulation, with 60/40 and 70/30 systems 1.6 and 3.9 times higher, respectively, than the system with the highest amount of plasticizer (50/50). It is well known that plasticizers ease the processability of polymeric samples and lower torque and temperatures are expected through the mixing due to a softening of the sample as their content increases [24].

\section{Dynamic Mechanical Thermal Analysis (DMTA)}

Figure 3A shows the effect of temperature from -50 to $150{ }^{\circ} \mathrm{C}$ on both viscoelastic moduli for the blend with a RO/GLY ratio of 60/40. Due to excessive flabbiness $(50 / 50)$ or rigidity (70/30), blends with other RO/GLY rations did not lead to reliable experimental data. All blends softened as they were heated, which was reflected in a global decrease in both the elastic (E') and viscous (E") moduli when subjected to DMTA tests (data not shown). A marked decrease higher than two orders of magnitude was observed in both $\mathrm{E}^{\prime}$ and $\mathrm{E}^{\prime \prime}$, leading to a minimum approximately at $75^{\circ} \mathrm{C}$. From then on, a slight increase and a tendency onto a steady value were observed. This behavior is qualitatively similar to that displayed by other blends including biomass from different sources such as soy, plasma porcine, among others $[23,24,30]$. Thermoplastic behavior generally implies a softening of the material, as reflected by the decrease in both viscoelastic moduli. This is typically associated with the fading of secondary interactions (e.g., hydrogen bonds) when heating a polymer (i.e., proteins).
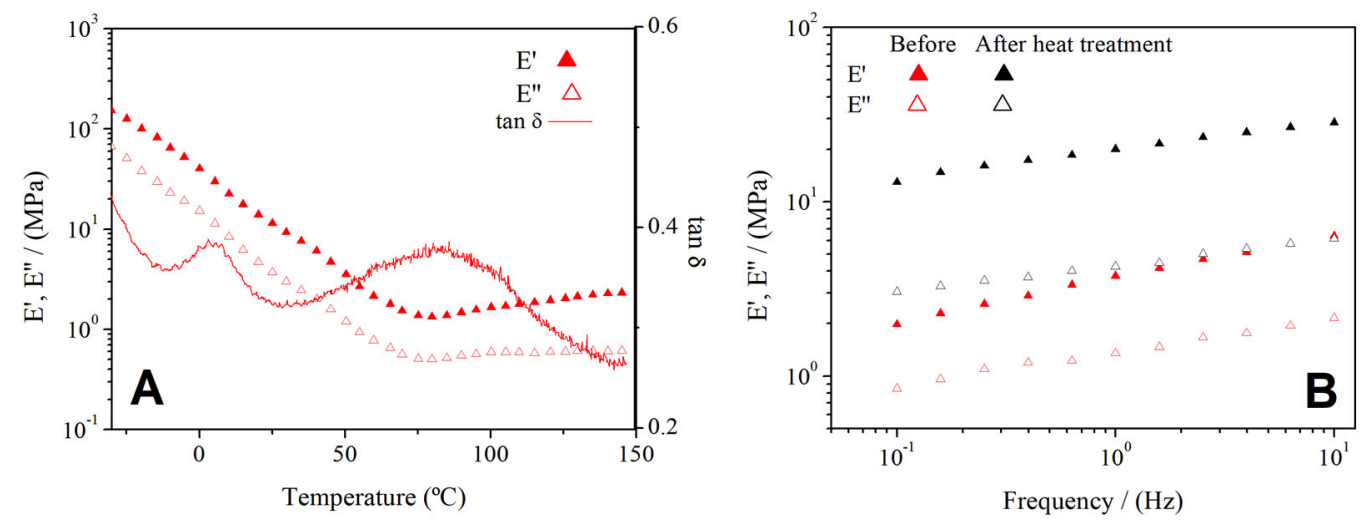

Figure 3. Evolution of elastic ( $\left.E^{\prime}\right)$ and viscous ( $\left.E^{\prime \prime}\right)$ moduli with temperature (A) and with frequency before and after heat treatment (B) for the blend with a RO/GLY ratio of 60/40. 
When observing the evolution of the loss tangent ( $\tan \delta$ ) along with the heating (Figure 3A), it is quite clear that in spite of the softening previously commented when heating, the sample reinforced its elastic character over its viscous one. Thus, $\tan \delta$ decreased from 0.58 to 0.26 . Moreover, two peaks were also observed for tan $\delta$, one around $0{ }^{\circ} \mathrm{C}$ and the other above $82{ }^{\circ} \mathrm{C}$, which indicate thermal transitions of the material and show the heterogeneity of the sample. As a matter of fact, when cooled down to room temperature, greater $\mathrm{E}^{\prime}$ and $\mathrm{E}^{\prime \prime}$ were obtained due to the formation of physical interactions (e.g., hydrogen bonds), as observed in Figure 3B for frequency sweep tests performed at $20^{\circ} \mathrm{C}$ before and after the whole DMTA test.

Figure 3B shows the dependence of the viscoelastic moduli on frequency from 0.1 to $10 \mathrm{~Hz}$ before and after the heat treatment for a $60 / 40 \mathrm{RO} / \mathrm{GLY}$ ratio. The frequency sweep tests confirm the marked elastic character, since the elastic moduli is above the viscous moduli within the entire range of frequency studied. However, a slight dependence of the viscoelastic moduli on frequency is manifested in the E'-frequency slope, being 0.25 before the heat treatment and 0.16 after the heat treatment (Figure 3B). Despite the predominant elastic behavior, the blends obtained are injectable, since they behave similarly to other protein blends with successful injection molding results [31]. Moreover, these results also evidence the effect of temperature on the microstructure of the blends, decreasing the dependence on frequency, which reflects a lower protein chain mobility [32]. These results evidence the suitability of thermal processing methods for these blends.

\subsubsection{Bioplastics}

Previous blends were injection molded obtaining different bioplastic materials. A picture of the resulting bioplastics can be found in the Supplementary Material (Figure S2. Visual appearance of RO/GLY bioplastics at different ratios (from left to right: 50/50, $60 / 40,70 / 30$ ) molded at $120{ }^{\circ} \mathrm{C}$ ).

\section{Dynamic Mechanical Thermal Analysis (DMTA)}

Blends with different RO/GLY ratios (50/50, 60/40, 70/30) were subjected to injection molding at a mold temperature of $120^{\circ} \mathrm{C}$, a temperature much higher than the minimum detected in the DMTA tests of the blends $\left(\sim 75^{\circ} \mathrm{C}\right)$. Figure 4 shows the DMTA tests carried out from -30 to $180{ }^{\circ} \mathrm{C}$ for the different bioplastics obtained. As observed for blends, a softening of all the bioplastics took place as they were heated, which can be associated with the disruption of the secondary structure of proteins caused by the increase in temperature. However, the decrease in the viscoelastic moduli observed in the bioplastic systems was much less pronounced than in the blends, due to the strengthening induced in the samples during the injection molding process at high temperatures and pressures. During this softening, a peak in tan $\delta$ was observed at around $80{ }^{\circ} \mathrm{C}$ for all samples, pointing out a thermal transition of these materials (data not shown). Moreover, contrary to blends, no minimum was detected during the thermal treatment which implied that no further strengthening would be expected through more exhaustive conditions. It seems that the greatest thermosetting potential was already achieved during the injection-molding processing of the seaweed-based blends. All bioplastics displayed a much more cohesive structure than the original blends and could be tested correctly, tending towards steady values at high temperatures $\left(\sim 125^{\circ} \mathrm{C}\right)$. Thus, higher content in seaweed resulted in greater viscoelastic moduli, observing a growing sequence for both $\mathrm{E}^{\prime}$ and $\mathrm{E}^{\prime \prime}$ with the RO/GLY ratio $(50 / 50<60 / 40<70 / 30)$ during the whole DMTA test. A similar response when increasing the biomass content in bioplastics made from proteins and GLY has already been observed $[23,24]$. The observed evolution of $\mathrm{E}^{\prime}$ and E" with RO/Gly ratio was also found in injected bioplastics from microalgae, which was attributed to the promotion of protein-protein interactions when the plasticizer content decreased [33,34]. It should be noticed that López-Rocha et al. [33] did not find the mentioned biomass content-viscoelastic properties correlation for blends, but also after the injection molding process. Samples were submitted to drastic temperature and pressure conditions when injected, which 
promoted the strengthening of the samples in a more efficient way than just mixing at room temperature. Therefore, when considering the value of the elastic modulus at $20{ }^{\circ} \mathrm{C}\left(\mathrm{E}_{20}^{\prime}\right)$, the 60/40 system experienced an increase from around 14 (blend) to 219 (bioplastic) $\mathrm{MPa}$ as a result of the injection molding process.
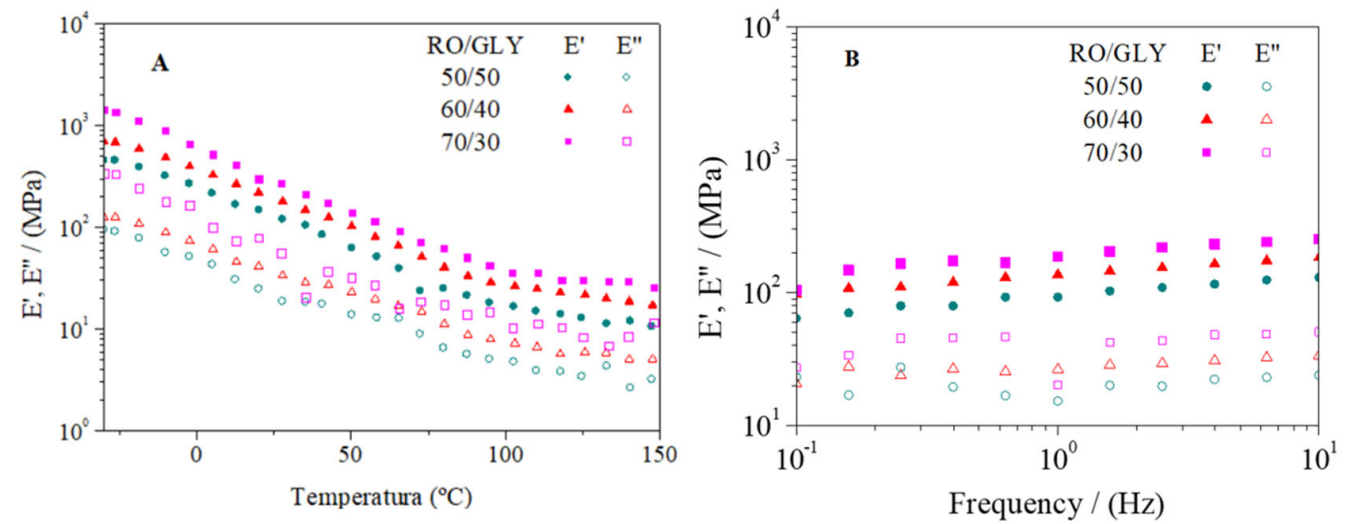

Figure 4. Evolution of viscoelastic moduli with temperature (A) and frequency (B) for bioplastics with different RO/GLY ratio (50/50, 60/40, 70/30).

Tensile Tests

Tensile tests were carried out on the bioplastics with different RO/GLY ratios at constant elongation rate of $1 \mathrm{~mm} \cdot \mathrm{min}^{-1}$ to assess the effect of the biomass content on their mechanical properties. Figure 5 shows the stress-strain curves produced by the three systems studied, showing an initial linear elastic region at lower strains in which the slope corresponds to the Young's modulus, E. When certain yield stress was exceeded, the slope began to descend as plastic deformation took place. Once the stress reached a maximum value $\left(\sigma_{\max }\right)$, the slope decayed abruptly, especially for the $70 / 30$ system, which implied the breakage of the probe at a maximum deformation $\varepsilon_{\max }$. In the systems studied, it is observed that as the content of seaweed in the sample increased, and the rigidity of the materials also increased, requiring higher stresses to achieve the same degree of deformation, which implies greater resistance to breakage. Moreover, this plot also showed the higher tenacity obtained for the ratio $70 / 30$.

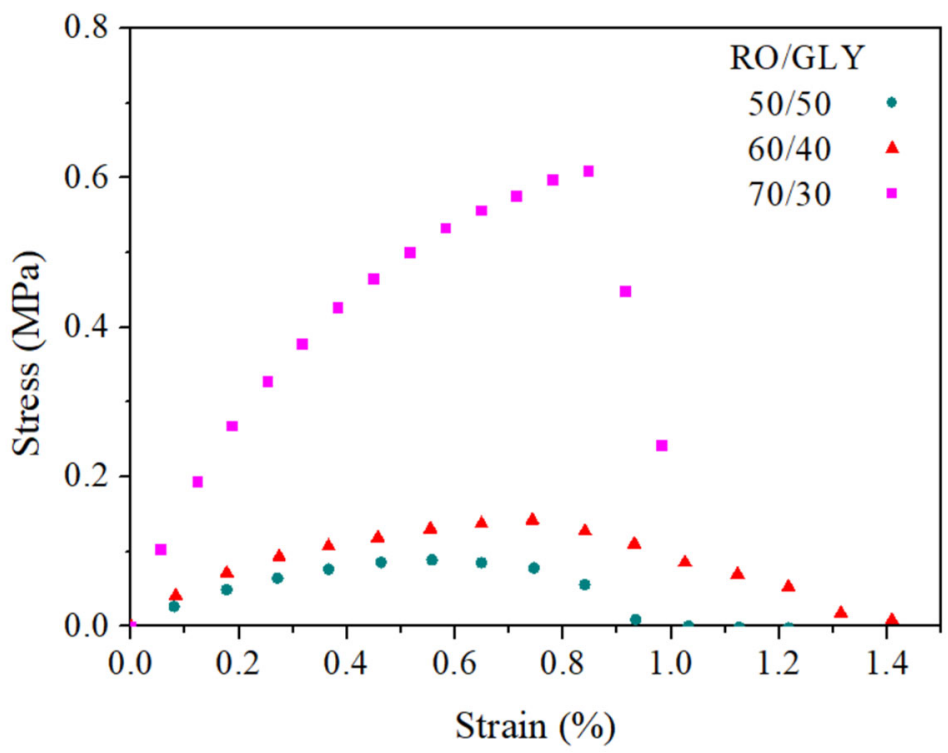

Figure 5. Stress-strain curves for bioplastics with different RO/GLY ratios (50/50, 60/40 and 70/30). 
Mechanical properties estimated from tensile tests for bioplastics with different RO/GLY ratios $(50 / 50,60 / 40$ and $70 / 30)$ are shown in Table 2 . It is observed that both $\mathrm{E}$ and $\sigma_{\max }$ increased with the content of seaweed in the formulation of the bioplastic, displaying an exponential increase that led to a remarkable increase for the $70 / 30$ system. This evolution is in line with that observed for the viscoelastic properties of the systems obtained previously from the DMTA tests, although the evolution of E' and E" with RO/GLY was more gradual than for the tensile properties. Regarding the $\varepsilon_{\max }$, no clear evolution could be perceived, and the 60/40 system displayed the greatest deformability. Other authors have found a similar evolution for $\mathrm{E}$ and $\sigma_{\max }$ when increasing biomass content in injection molded bioplastics [24], although they also detected an increase in $\varepsilon_{\max }$. The lower $\varepsilon_{\max }$ obtained for $70 / 30$ should be related to its greater rigidity due to the higher strengthening achieved during injection molding, as commented before. This should be explained on basis of the lack of plasticizer, which allowed greater interaction between the polymeric chains (e.g., proteins, carbohydrates) of the material, leading to a more rigid and resistant structure. This phenomenon of $\varepsilon_{\max }$ variation has been reproduced by other authors for starch-based bioplastics. The plasticizer replaced existing intermolecular bonds in the material's structure with hydrogen bonds, which reduces stiffness and allows flexibility, so the higher the amount of plasticizer, the greater the deformation capacity [35]. However, when the plasticizer concentration exceeds a critical value, the anti-plasticizer phenomenon can occur. In these cases, too much plasticizer in the mix can excessively weaken the cohesion between the polymer chains making it too brittle and resulting in less elongation [36].

Table 2. Mechanical parameters (Young's modulus (E), maximum stress ( $\left.\sigma_{\max }\right)$ and maximum strain $\left.\left(\varepsilon_{\max }\right)\right)$ for bioplastics with different RO/GLY ratios $(50 / 50,60 / 40,70 / 30)$. Different letters within a column indicate significant differences $(p<0.05)$.

\begin{tabular}{cccc}
\hline RO/GLY & E (MPa) & $\varepsilon_{\max }(\%)$ & $\boldsymbol{\sigma}_{\max }(\mathbf{M P a})$ \\
\hline $50 / 50$ & $0.40 \pm 0.14^{\mathrm{a}}$ & $0.88 \pm 0.07^{\mathrm{a}}$ & $0.089 \pm 0.021^{\mathrm{a}}$ \\
\hline $60 / 40$ & $0.70 \pm 0.10^{\mathrm{b}}$ & $1.49 \pm 0.21^{\mathrm{b}}$ & $0.15^{\mathrm{a}} \pm 0.03^{\mathrm{b}}$ \\
\hline $70 / 30$ & $2.61 \pm 0.51^{\mathrm{c}}$ & $0.74 \pm 0.12^{\mathrm{a}}$ & $0.68^{\mathrm{a}} \pm 0.06^{\mathrm{c}}$ \\
\hline
\end{tabular}

Similar profiles are observed in other bioplastics made with proteins such as soy protein or porcine plasma protein $[23,24]$.

\section{Water Uptake Capacity (WUC)}

Figure 6 shows the dependence of water uptake capacity (WUC) and soluble matter loss (SML) on the RO/GLY ratio of bioplastics studied. There was a significant and progressive decrease in WUC values when increasing the seaweed content in the bioplastic, going from around $260 \%$ to $180 \%$ when the RO/GLY ratio increased from 50/50 to 70/30. Similar values and evolution with biomass content were observed in bioplastics from a microalgae consortium by López Rocha et al. [33]. The greater WUC displayed by the 50/50 system can be associated with its higher glycerol content, which promotes the formation of a porous structure that may improve the absorption process, as hydrophilic GLY tends to pass onto the aqueous immersion media $[23,24]$. The greater rigidity and resistance measured for the 70/30 system inhibited the swelling of the bioplastic, limiting-as a consequence-its ability to absorb water. 


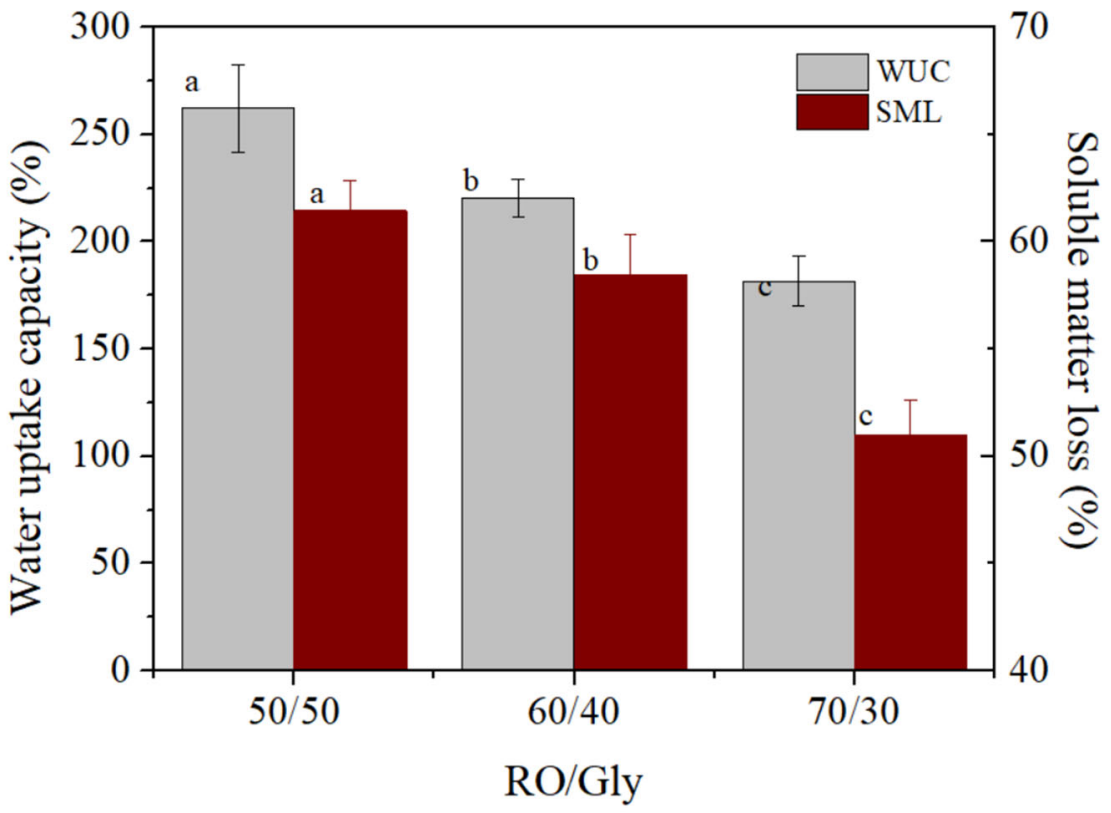

Figure 6. Water uptake capacity and soluble matter loss for the RO/Gly systems: 50/50, 60/40 and 70/30. Different letters (a, b, c) within the same column parameter (WUC or SML) indicate significant differences $(p<0.05)$.

Regarding the SML, a tendency to decrease as the RO/GLY ratio increased was detected, being significant for the 70/30 system: both 50/50 and 60/40 bioplastics lost around $60 \%$ of mass when immersed for $24 \mathrm{~h}$, while the $70 / 30$ bioplastic lost around $50 \%$, which is coherent with a greater number of interactions strengthening the material. Most of the SML is due to the loss of glycerol, which has a highly hydrophilic behavior [37]. However, some of the biomass ( $20-30 \%)$ was also lost during immersion as the SML was always higher than the original percentage of GLY in the formulation.

\section{Scanning Electron Microscopy (SEM)}

Figure 7 shows the images obtained by SEM for each of the bioplastics generated after a freeze drying process after studying the water uptake capacity. By increasing the percentage of seaweed in the formulation, the surface became less porous, which was much more noticeable in the case of the 70/30 system. Furthermore, the lower presence of pores in the structure as the RO/GLY ratio increased was strongly affected by the WUC results (Figure 6): the structure of the 50/50 system was more heterogeneous and showed many structural irregularities and pores through which water can enter, while the 70/30 system showed a lower amount of pores and interstices. Moreover, this also agrees with the viscoelastic and mechanical properties already reported, as the 70/30 system possessed higher viscoelastic moduli, rigidity and resistance supported by a more compact structure, with a lower porosity.

\subsection{Influence of Molding Temperature in Bioplastic Properties}

Bioplastics with a RO/GLY ratio equal to $70 / 30$ were processed at different molding temperatures $\left(\mathrm{T}_{\mathrm{m}}: 90,120\right.$ and $\left.150{ }^{\circ} \mathrm{C}\right)$ to assess their effect on their properties. Previously, some authors have already indicated that $\mathrm{T}_{\mathrm{m}}$ is the processing parameter that commonly affects the properties of bioplastics to a greater extent when injection molded [23]. 


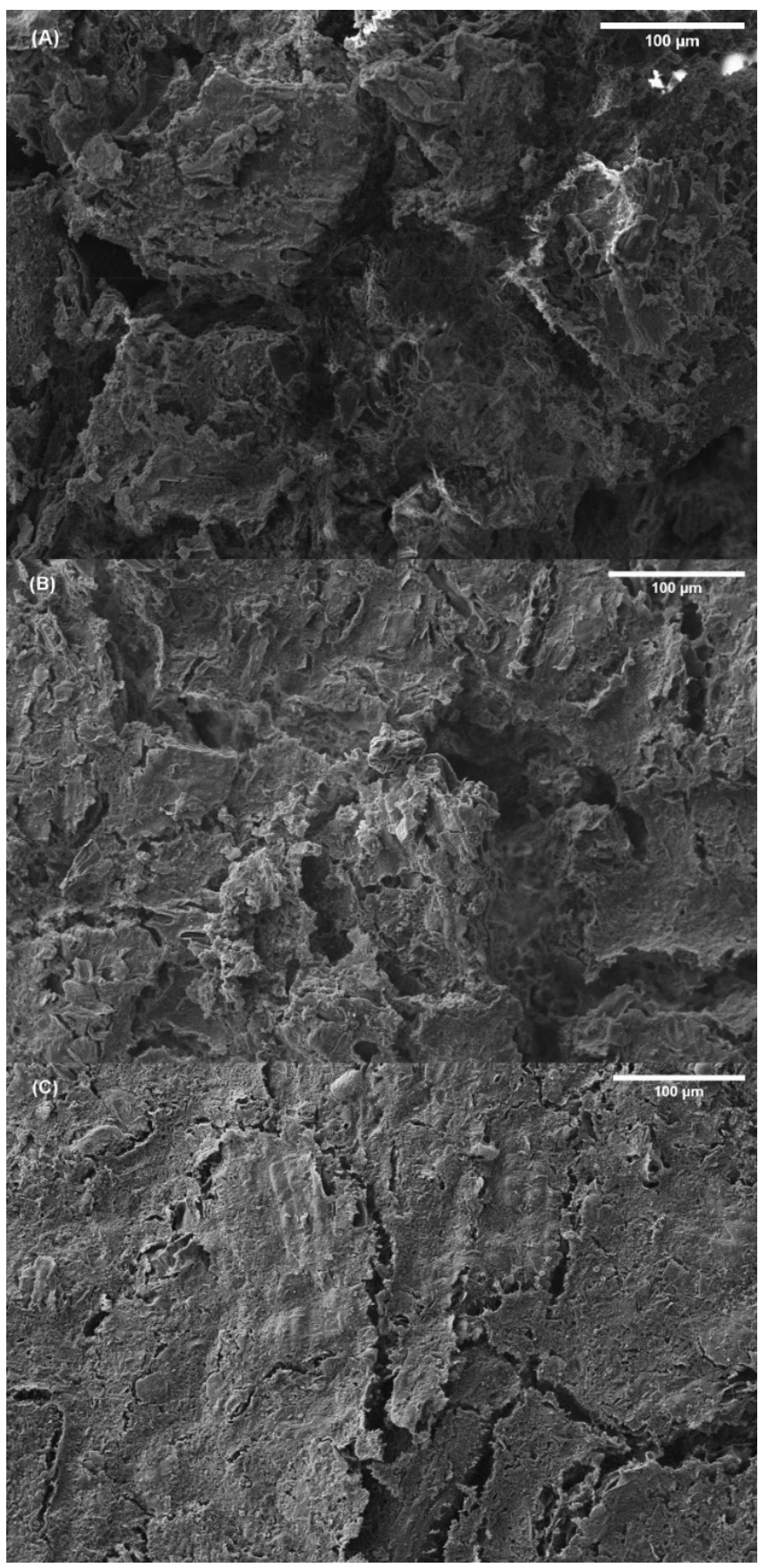

Figure 7. Scanning electron microscopy images of RO/GLY 50/50 (A), 60/40 (B) and 70/30 (C) systems prepared at $120^{\circ} \mathrm{C}$ with a magnification of $200 \times$.

\subsubsection{Dynamic Mechanical Thermal Analysis (DMTA)}

Figure 8 shows the dependence of viscoelastic moduli on temperature (A) and frequency (B) for $70 / 30$ bioplastics molded at different temperatures $\left(90,120,150{ }^{\circ} \mathrm{C}\right)$.

As observed in Figure 4A, all samples processed at different molding temperatures displayed the same qualitative evolution: $E^{\prime}$ and $E^{\prime \prime}$ values, since they decreased when heating the samples and tended to a plateau value around $120^{\circ} \mathrm{C}$. Other authors have previously studied the effect of molding temperature in other bioplastic systems. Thus, Fernández-Espada et al. studied bioplastics based on soy protein molded at 40,80 and $120{ }^{\circ} \mathrm{C}$, not obtaining significant differences in the evolution of $\mathrm{E}^{\prime}$ or $\mathrm{E}^{\prime \prime}$ moduli with temperature [23]. However, no great quantitative differences were observed for the 70/30 sample when molded at different temperatures, which would indicate that all molding 
temperatures used during the holding stage in the injection molding process were high enough to achieve the greatest thermosetting potential of seaweed bioplastics. It should be noted that the sample molded at the highest temperature displayed slightly lower values for both viscoelastic moduli during the whole temperature test, which could be related to the possible degradation of the biomass at $150{ }^{\circ} \mathrm{C}$.
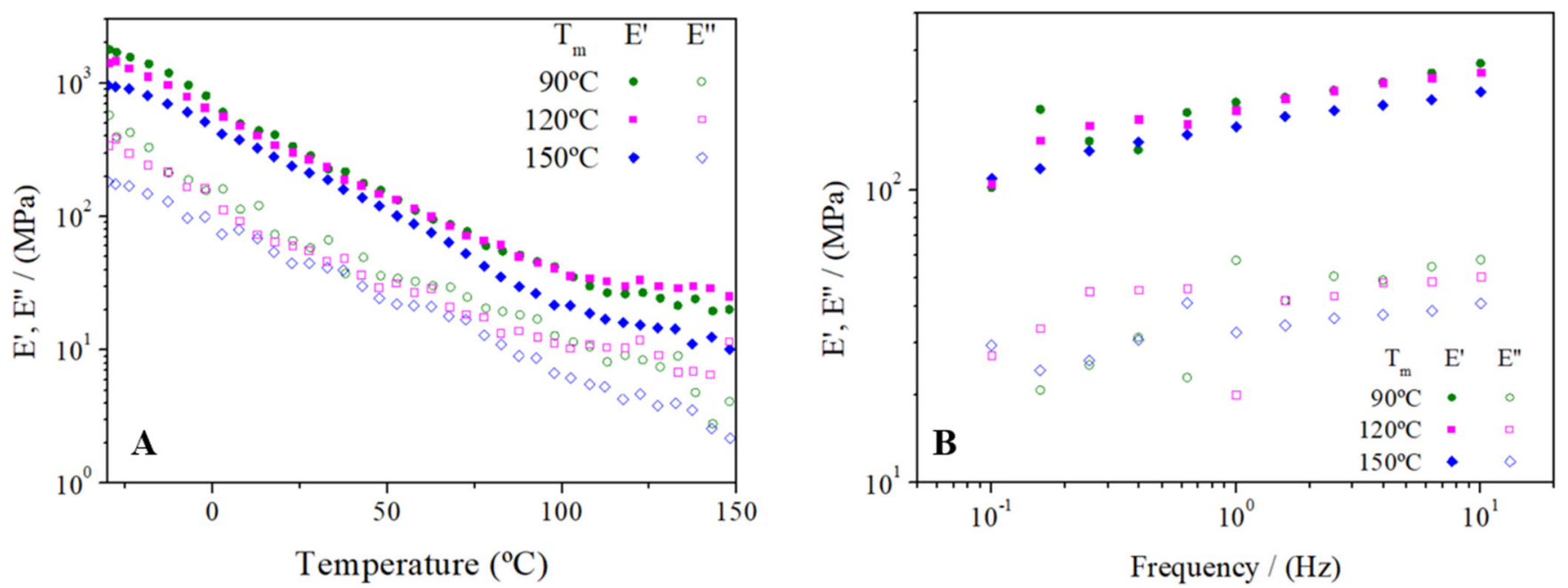

Figure 8. Dependence of viscoelastic moduli on temperature (A) and frequency (B) for RO/GLY $70 / 30$ bioplastics processed at different molding temperature $\left(90,120\right.$ and $\left.150{ }^{\circ} \mathrm{C}\right)$.

The frequency sweep tests performed on the 70/30 samples molded at different $\mathrm{T}_{\mathrm{m}}$ were quite similar (Figure 4B), although the system molded at the highest temperature showed slightly lower $\mathrm{E}^{\prime}$ and $\mathrm{E}^{\prime \prime}$ values. Moreover, a significant increase was observed in the loss tangents values ( $\tan \delta$ ) when increasing $\mathrm{T}_{\mathrm{m}}$ for the $70 / 30$ system $(0.22 \pm 0.04$, $0.26 \pm 0.01$, and $0.32 \pm 0.01$ for 90,120 and $150{ }^{\circ} \mathrm{C}$, respectively), which implied a loss of the elasticity of the material when molded at higher temperatures. The effects of molding temperature in soy protein-based bioplastics have already been studied by Paetau et al. [38], obtaining similar results. Increasing the temperature favors the crosslinking of the polymer fibers, which makes the material stiffer to some extent. After a certain temperature, proteins are degraded and a decrease in mechanical properties begins to be observed.

\subsubsection{Tensile Properties}

Figure 9 and Table 3 show the stress-strain curves and the main mechanical parameters, respectively, $\left(\mathrm{E}, \sigma_{\max }, \varepsilon_{\max }\right)$ for bioplastics with a RO/GLY ratio of 70/30 processed at different molding temperature $\left(90,120\right.$ and $\left.150{ }^{\circ} \mathrm{C}\right)$. The stress-strain curves of the three systems are similar in shape, with an initial linear elastic behavior, the slope of which decayed slightly until reaching the maximum stress when the material ruptured. Greater stresses are required to deform the sample processed at $120{ }^{\circ} \mathrm{C}$ when compared to the rest of mold temperatures, which can resist stresses up to $0.7 \mathrm{MPa}$; twice the value of that can be applied to the rest of the samples. The initial increase from 90 to $120{ }^{\circ} \mathrm{C}$ should be related to a certain strengthening of the sample due to thermally induced interactions (e.g., disulfide bonds), while the decrease in the stress-strain curve from 120 to $150{ }^{\circ} \mathrm{C}$ should be associated with the previously commented degradation that negatively affects the mechanical properties [23]. 


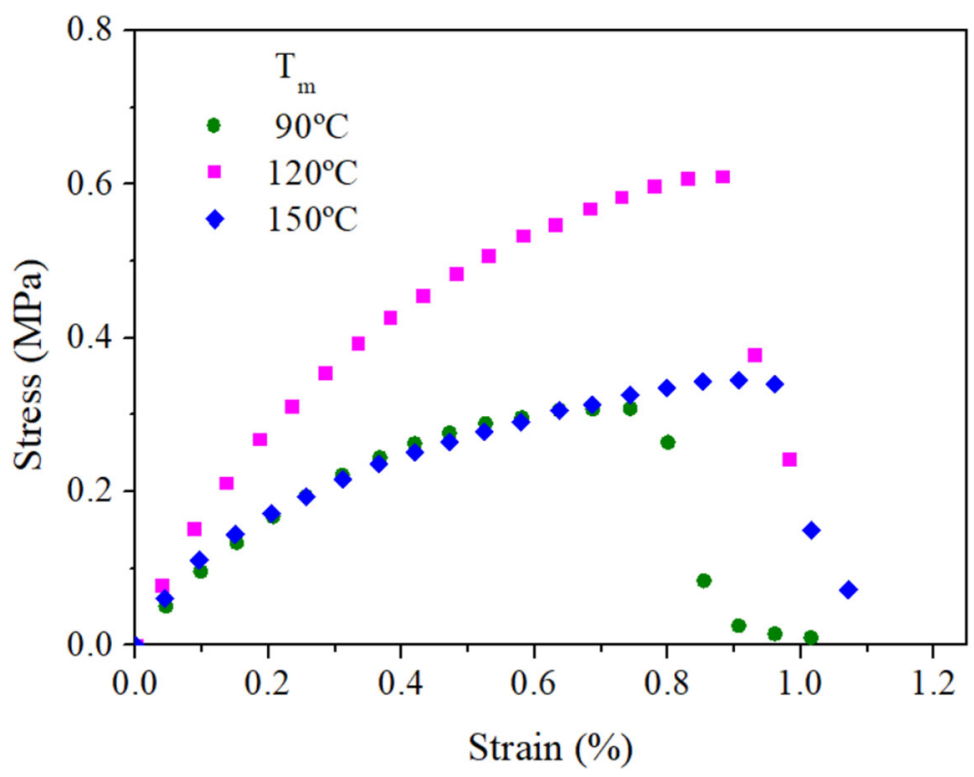

Figure 9. Tensile properties of bioplastics (RO/GLY: 70/30) processed at different molding temperature $\left(90,120\right.$ and $\left.150{ }^{\circ} \mathrm{C}\right)$.

Table 3. Mechanical parameters (Young's modulus (E), maximum stress ( $\left.\sigma_{\max }\right)$ and maximum strain $\left.\left(\varepsilon_{\max }\right)\right)$ of bioplastics (RO/GLY: 70/30): for different molding temperature $\left(90,120\right.$ and $150{ }^{\circ} \mathrm{C}$ ). Different letters within the same column parameter (WUC or SML) indicates significant differences $(p<0.05)$.

\begin{tabular}{cccc}
\hline $\begin{array}{c}\text { Molding } \\
\text { Temperature }\left({ }^{\circ} \mathbf{C}\right)\end{array}$ & E (MPa) & $\boldsymbol{\sigma}_{\max }(\%)$ & $\varepsilon_{\max }(\mathbf{M P a})$ \\
\hline 90 & $1.60 \pm 0.14^{\mathrm{a}}$ & $0.73 \pm 0.002^{\mathrm{a}}$ & $0.33 \pm 0.022^{\mathrm{a}}$ \\
\hline 120 & $2.61 \pm 0.51^{\mathrm{b}}$ & $0.74 \pm 0.12^{\mathrm{a}}$ & $0.68 \pm 0.057^{\mathrm{b}}$ \\
\hline 150 & $1.47 \pm 0.17^{\mathrm{a}}$ & $0.69 \pm 0.32^{\mathrm{a}}$ & $0.36 \pm 0.045^{\mathrm{a}}$ \\
\hline
\end{tabular}

\subsubsection{Water Uptake Capacity}

Regarding the WUC, the WUC slightly decreases (Figure 10) the molding temperature increases, being $189.1 \pm 6.2 \%$ for the system molded at $90{ }^{\circ} \mathrm{C}, 181.5 \pm 11.6 \%$ for the $120^{\circ} \mathrm{C}$ and $166.8 \pm 2.0 \%$ for the $150{ }^{\circ} \mathrm{C}$ molded system. This effect of temperature on WUC was observed in soy-based bioplastics [23] and was related to the formation of thermally induced interactions that take place during the injection molding. The lowering in WUC is observed from 90 to $150{ }^{\circ} \mathrm{C}$, in spite of the lower viscoelastic moduli and rigidity measured for the sample molded at $150^{\circ} \mathrm{C}$.

No significant differences were observed in the SML values of the systems with $T_{m}$, as all values were around $51.5 \%$, which implies that molding temperature does not exert much influence on soluble matter loss. Different letters within the same column parameter (WUC or SML) indicate significant differences $(p<0.05)$.

\subsubsection{Scanning Electron Spectroscopy}

Figure 11 shows the SEM images for bioplastics with a RO/GLY ratio of 70/30 processed at different molding temperatures. Some differences were found between the systems, with the structure of the bioplastic molded at 90 and $150{ }^{\circ} \mathrm{C}$ showing greater irregularities and pores than the one molded at $120^{\circ} \mathrm{C}$. These imperfections may be related to a lower degree of cross-linking, resulting in a lower dimensional stability. The smoother and more compact structure observed for the system molded at $120^{\circ} \mathrm{C}$ should be related to its lower water uptake capacity and higher viscoelastic properties. 


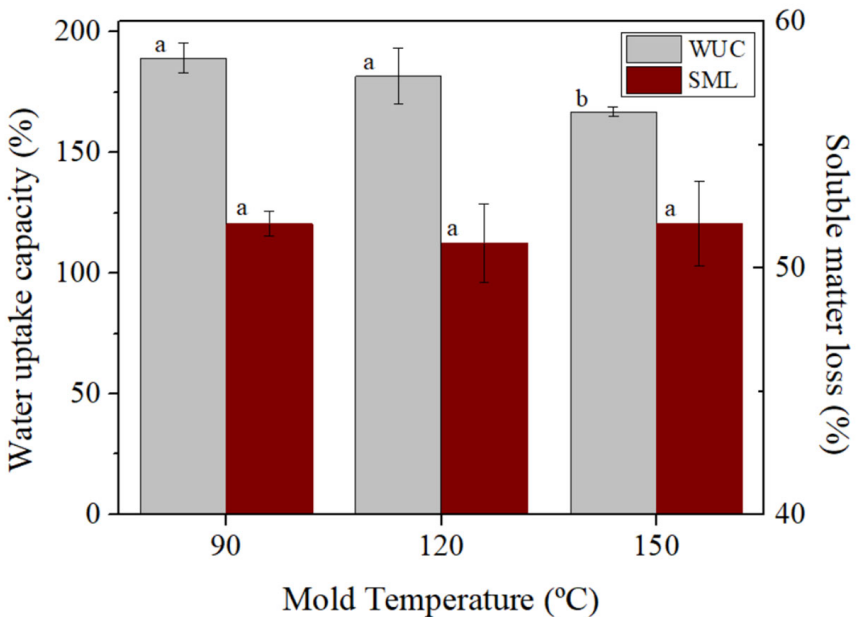

Figure 10. Water uptake capacity and soluble matter loss of the RO/Gly systems 70/30 at different molding temperature $\left(90,120\right.$ and $\left.150{ }^{\circ} \mathrm{C}\right)$. Different letters $(\mathrm{a}, \mathrm{b})$ within the same column parameter (WUC or SML) indicate significant differences $(p<0.05)$.

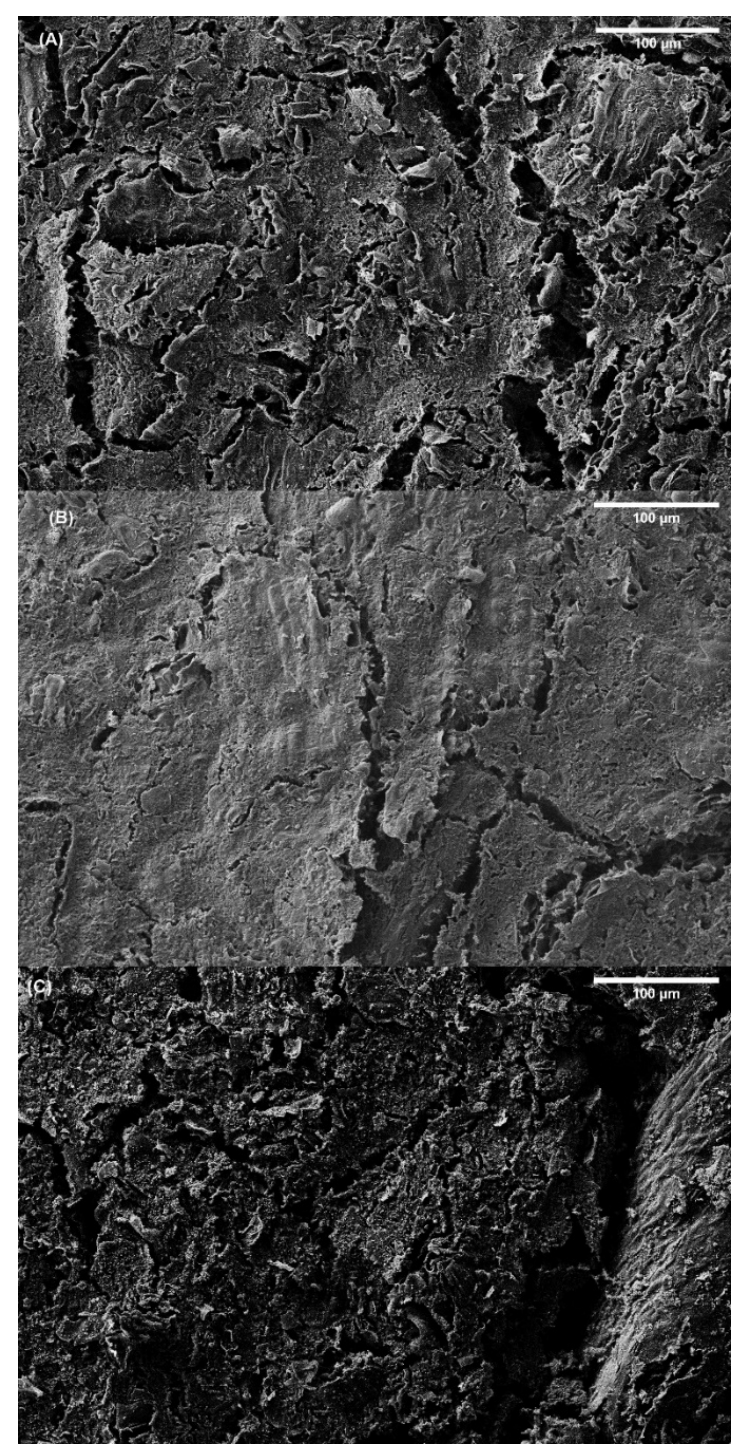

Figure 11. Scanning electron spectroscopy images of RO/GLY $70 / 30$ bioplastics molded at $90{ }^{\circ} \mathrm{C}(\mathbf{A})$, $120^{\circ} \mathrm{C}(\mathbf{B})$ and $150{ }^{\circ} \mathrm{C}(\mathrm{C})$ with a magnification of $200 \times$. 


\section{Conclusions}

The invasive seaweed Rugulopteryx okamurae can be used to produce bioplastics through injection molding employing glycerol as plasticizer. The higher the content of seaweed, the greater the viscoelastic properties, rigidity and resistance the bioplastics display. Thus, the sample with $\mathrm{RO} /$ Gly ratio of 70/30 displayed the higher values of those properties when compared to $50 / 50$ or $60 / 40$ ratios.

Regarding the DMA response, typical thermoplastic behavior was shown, as samples softened when heated until a plateau was achieved at high temperatures. The elastic behavior always prevailed over the viscous one since the storage modulus of every system remained above the loss modulus. The WUC was lowered as the biomass content increased, due to the lower presence of the hydrophilic plasticizer employed. However, some biomass was lost during the immersion of the bioplastic samples, which can be explained by the relatively low mechanical properties of all systems when compared to those obtained from other sources. In relation to this, the greater the mechanical stability of the material, the lower WUC, because the polymers are expected to be more cross-linked and there are greater impediments for water to be in the pores of the structure and bond. This also resulted in a lower SML. The impact of the mold temperature was more noticeable in the tensile test, where the system molded at $120^{\circ} \mathrm{C}$ stood out slightly. A slight lowering of water absorption capacity was detected when increasing the mold temperature, although its effect was not very significant when compared to the effect of the formulation (RO/GLY ratio).

The results obtained in the present work are very promising, although further research should be performed to improve the mechanical properties of Rugulopteryx okamurae seaweed-based bioplastics. The formulation of composites with other biodegradable polymers and the studies of effects on different processing conditions may be a way to achieve that purpose and to find new utilities.

Supplementary Materials: The following are available online at https:/ / www.mdpi.com/article/10 .3390 / polym14020355/s1, Figure S1: Visual appearance of RO/GLY blends at different ratios (from left to right: 50/50, 60/40, 70/30). Figure S2: Visual appearance of RO/GLY bioplastics at different ratios (from left to right: $50 / 50,60 / 40,70 / 30$ ) molded at $120^{\circ} \mathrm{C}$.

Author Contributions: Conceptualization, M.F. and C.B.; methodology, M.F. and C.B.; software, I.S.; validation, M.F. and C.B.; formal analysis, M.F. and C.B.; investigation, I.S.; resources, C.B.; data curation, I.S.; writing-original draft preparation, I.S.; writing-review and editing, M.F. and C.B.; visualization, C.B.; supervision, M.F. and C.B.; project administration, A.G., C.B.; funding acquisition, A.G. and C.B. All authors have read and agreed to the published version of the manuscript.

Funding: This study was financially supported by the "FEDER/Ministerio de Ciencia e InnovaciónAgencia Estatal de Investigación", through the project RTI2018-097100-B-C21, and through the PhD Grant: PRE2019-089815.

Institutional Review Board Statement: Not applicable.

Informed Consent Statement: Not applicable.

Data Availability Statement: The data presented in this study are available on request from the corresponding author.

Acknowledgments: The authors acknowledge the University of Seville for the VPPI-US grant (Ref.II.5) to Manuel Felix, and also the Andalusian goberment and the European commission for funding the contract of Ismael Santana through the Youth Employment Initiative (EJ5-13-1). The authors also thank CITIUS for granting access to and their assistance with the Microscopy service. Finally, the authors also kindly thank Ismael Hachero (from IFAPA El Toruño) for providing the raw material used in this study. Moreover, the authors would also like to thank the Spanish "Ministerio de Ciencia e Innovación (MCI)/Agencia Estatal de Investigación (AEI)/Fondo Europeo de Desarrollo Regional (FEDER, UE)" for the financial support provided through the funding of the RTI2018-097100-B-C21 (MCI/AEI/FEDER, UE) project. 
Conflicts of Interest: The authors declare no conflict of interest. The funders had no role in the design of the study; in the collection, analyses, or interpretation of data; in the writing of the manuscript, or in the decision to publish the results.

\section{References}

1. Hwang, I.-K.; Lee, W.J.; Kim, H.-S.; De Clerck, O. Taxonomic reappraisal of Dilophus okamurae (Dictyotales, Phaeophyta) from the western Pacific Ocean. Phycologia 2009, 48, 1-12. [CrossRef]

2. $\quad$ Dawson, E.Y. Notes on Some Pacific Mexican Dictyotaceae. Bull. Torrey Bot. Club 1950, 77, 83. [CrossRef]

3. Agatsuma, Y.; Kuwahara, Y.; Taniguchi, K. Life cycle of Dilophus okamurae (Phaeophyceae) and its associated invertebrate fauna in Onagawa Bay, Japan. Fish. Sci. 2005, 71, 1107-1114. [CrossRef]

4. García-Gómez, J.C.; Florido, M.; Olaya-Ponzone, L.; Rey Díaz de Rada, J.; Donázar-Aramendía, I.; Chacón, M.; Quintero, J.J.; Magariño, S.; Megina, C. Monitoring Extreme Impacts of Rugulopteryx okamurae (Dictyotales, Ochrophyta) in El Estrecho Natural Park (Biosphere Reserve). Showing Radical Changes in the Underwater Seascape. Front. Ecol. Evol. 2021, 9, 1-18. [CrossRef]

5. García-Gómez, J.C.; Sempere-Valverde, J.; González, A.R.; Martínez-Chacón, M.; Olaya-Ponzone, L.; Sánchez-Moyano, E.; OstaléValriberas, E.; Megina, C. From exotic to invasive in record time: The extreme impact of Rugulopteryx okamurae (Dictyotales, Ochrophyta) in the strait of Gibraltar. Sci. Total Environ. 2020, 704, 135408. [CrossRef]

6. El Ayuntamiento de Tarifa ya ha Retirado Unas 400 Toneladas de Lagas Invasoras en el Último Mes. Available online: https: / / www.elestrechodigital.com/2020/08/19/el-ayuntamiento-de-tarifa-ya-ha-retirado-unas-400-toneladas-de-algasinvasoras-en-el-ultimo-mes / (accessed on 30 September 2021).

7. Shrivastava, A. Plastic Properties and Testing; Elsevier: Oxford, UK, 2018; ISBN 9780323395007.

8. Kalia, V.C.; Raizada, N.; Sonakya, V.; Kalia, V.C. Neena Raizada and V Sonakya. J. Sci. Ind. Res. 2000, 59, $433-445$.

9. Gahlawat, S.K.; Salar, R.K.; Siwach, P.; Duhan, J.S.; Kumar, S.; Kaur, P. Plant biotechnology: Recent advancements and developments. In Plant Biotechnology: Recent Advancements and Developments; Springer: Singapore, 2017; pp. 1-390. [CrossRef]

10. Schmaltz, E.; Melvin, E.C.; Diana, Z.; Gunady, E.F.; Rittschof, D.; Somarelli, J.A.; Virdin, J.; Dunphy-Daly, M.M. Plastic pollution solutions: Emerging technologies to prevent and collect marine plastic pollution. Environ. Int. 2020, 144, 106067. [CrossRef] [PubMed]

11. Cox, K.D.; Covernton, G.A.; Davies, H.L.; Dower, J.F.; Juanes, F.; Dudas, S.E. Human Consumption of Microplastics. Environ. Sci. Technol. 2019, 53, 7068-7074. [CrossRef]

12. Ashter, S.A. 5-Types of Biodegradable Polymers. In Introduction to Bioplastics Engineering; Elsevier: Oxford, UK, 2016 ; pp. 81-151. ISBN 9780323393966.

13. European Bioplastics Bioplastics Glossary. Available online: https:/ / www.european-bioplastics.org/glossary/ (accessed on 30 September 2021).

14. Thiruchelvi, R.; Das, A.; Sikdar, E. Materials Today: Proceedings Bioplastics as better alternative to petro plastic. Mater. Today Proc. 2021, 37, 1634-1639. [CrossRef]

15. Tauer, K. Fundamental principles of polymeric materials, second edition. Stephen L. Rosen. A volume in the SPE monograph series. A wiley-interscience publication. John Wiley \& Sons, Inc. 1993, 420 pages. Acta Polym. 1993, 44, 210. [CrossRef]

16. Wilson, A. Plasticisers: Principles and Practice; Institute of Materials: London, UK, 1995; ISBN 9780901716767.

17. Wypych, G. Handbook of Plasticizers, 3rd ed.; Elsevier Inc.: Amsterdam, The Netherlands, 2017; ISBN 9781895198973.

18. Vieira, M.G.A.; da Silva, M.A.; dos Santos, L.O.; Beppu, M.M.; Adeodato Vieira, M.G.; da Silva, M.A.; dos Santos, L.O.; Beppu, M.M.; Vieira, M.G.A.; da Silva, M.A.; et al. Natural-based plasticizers and biopolymer films: A review. Eur. Polym. J. 2011, 47, 254-263. [CrossRef]

19. Sikora, J.; Majewski, Ł.; Puszka, A. Modern Biodegradable Plastics-Processing and Properties: Part I. Materials 2020, 13 , 1986. [CrossRef]

20. Ashter, S.A. 7-Processing Biodegradable Polymers. In Introduction to Bioplastics Engineering; Elsevier: Oxford, UK, 2016; pp. 211-225. ISBN 9780323393966.

21. Ashter, S.A. 8-Extrusion of Biopolymers. In Introduction to Bioplastics Engineering; Elsevier: Oxford, UK, 2016; pp. 211-225. ISBN 9780323393966.

22. Jerez, A.; Partal, P.; Martínez, I.; Gallegos, C.; Guerrero, A. Rheology and processing of gluten based bioplastics. Biochem. Eng. J. 2005, 26, 131-138. [CrossRef]

23. Fernández-Espada, L.; Bengoechea, C.; Cordobés, F.; Guerrero, A. Thermomechanical properties and water uptake capacity of soy protein-based bioplastics processed by injection molding. J. Appl. Polym. Sci. 2016, 133, 1-10. [CrossRef]

24. Álvarez-Castillo, E.; Bengoechea, C.; Rodríguez, N.; Guerrero, A. Development of green superabsorbent materials from a by-product of the meat industry. J. Clean. Prod. 2019, 223, 651-661. [CrossRef]

25. Beacham, W. Algae-Based Bioplastics a Fast-Growing Market; ICIS: Maastricht, The Netherlands, 2010.

26. Mæhre, H.K.; Malde, M.K.; Eilertsen, K.E.; Elvevoll, E.O. Characterization of protein, lipid and mineral contents in common Norwegian seaweeds and evaluation of their potential as food and feed. J. Sci. Food Agric. 2014, 94, 3281-3290. [CrossRef] [PubMed] 
27. ISO-527-2:2012; Plastics—Determination of Tensile Properties—Part 2: Test Conditions for Moulding and Extrusion Plastics. ISO Central Secretariat: Geneva, Switzerland, 2012.

28. Cuadri, A.A.A.; Romero, A.; Bengoechea, C.; Guerrero, A. The Effect of Carboxyl Group Content on Water Uptake Capacity and Tensile Properties of Functionalized Soy Protein-Based Superabsorbent Plastics. J. Polym. Environ. 2018, 26, 2934-2944. [CrossRef]

29. Schneider, C.A.; Rasband, W.S.; Eliceiri, K.W. NIH Image to ImageJ: 25 years of image analysis. Nat. Methods 2012, 9, 671-675. [CrossRef] [PubMed]

30. Bier, J.M.; Verbeek, C.J.R.; Lay, M.C. Thermal transitions and structural relaxations in protein-based thermoplastics. Macromol. Mater. Eng. 2014, 299, 524-539. [CrossRef]

31. Felix, M.; Perez-Puyana, V.; Romero, A.; Guerrero, A. Development of protein-based bioplastics modified with different additives. J. Appl. Polym. Sci. 2017, 134, 45430. [CrossRef]

32. Ferry, J.D. Viscoelastic Properties of Polymers; Wiley: Hoboken, NJ, USA, 1980; ISBN 9780471048947.

33. López Rocha, C.J.; Álvarez-Castillo, E.; Estrada Yáñez, M.R.; Bengoechea, C.; Guerrero, A.; Orta Ledesma, M.T. Development of bioplastics from a microalgae consortium from wastewater. J. Environ. Manag. 2020, 263, 110353. [CrossRef]

34. Zeller, M.A.; Hunt, R.; Jones, A.; Sharma, S. Bioplastics and their thermoplastic blends from Spirulina and Chlorella microalgae. J. Appl. Polym. Sci. 2013, 130, 3263-3275. [CrossRef]

35. Sanyang, M.L.; Sapuan, S.M.; Jawaid, M.; Ishak, M.R.; Sahari, J. Effect of plasticizer type and concentration on tensile, thermal and barrier properties of biodegradable films based on sugar palm (Arenga pinnata) starch. Polymers 2015, 7, 1106-1124. [CrossRef]

36. Zhang, Y.; Rempel, C.; Liu, Q. Thermoplastic Starch Processing and Characteristics-A Review. Crit. Rev. Food Sci. Nutr. 2014, 54, 1353-1370. [CrossRef] [PubMed]

37. Félix, M.; Martín-Alfonso, J.E.; Romero, A.; Guerrero, A. Development of albumen/soy biobased plastic materials processed by injection molding. J. Food Eng. 2014, 125, 7-16. [CrossRef]

38. Paetau, I.; Chen, C.Z.; Jane, J.L. Biodegradable plastic made from soybean products. 1. Effect of preparation and processing on mechanical-properties and water-absorption. Ind. Eng. Chem. Res. 1994, 33, 1821-1827. [CrossRef] 